\title{
Internetês: neologismos gírios nas redes sociais ${ }^{1}$
}

\author{
Internetese: slang neologisms in social networks
}

\author{
Flavio Biasutti Valadares* \\ Mateus Rodrigues de Moura**
}

Resumo: O artigo trata de gírias criadas e usadas nas redes sociais. Objetiva analisar neologismos gírios e estabelecer como o ciberespaço contribui para a formação de novos termos a partir das novas configurações de interação observadas com o advento das redes sociais. Baseia-se na Teoria da Variação e Mudança Linguística (LABOV, 1994, 2008), nos conceitos sobre gírias (PRETI, 2006) e nos estudos sobre hipertexto (MARCUSCHI, 2005). Como procedimentos metodológicos, analisa gírias efetivamente criadas pelas e nas redes sociais, busca descrevê-las em diversos aspectos e traça 0 perfil do usuário de tais neologismos, a partir da formulação de categorias de análise para interpretação dos dados coletados. Para tanto, utiliza a pesquisa quantitativoqualitativa, sob o viés exploratório, por meio de amostras retiradas das redes sociais. Conclui-se, por meio da análise dos dados coletados, que o internetês é, de fato, um conjunto neológico da internet e que a gíria é uma variação observada pelo que representa sua adoção e uso.

Palavras-chave: Sociolinguística. Gírias. Hipertexto. Internetês.

\begin{abstract}
This paper deals with slangs created and used in social networks. It aims at analyzing slang neologisms and determining the contribution of the cyberspace for the formation of new terms based on new configurations of interaction observed with the emergence of social networks. It is grounded on the Theory of Linguistic Variation and Change (LABOV, 1994, 2008), in Preti's conception of slangs (PRETI, 2006) and in studies of hypertext (MARCUSCHI, 2005). Using methodological procedures, it analyzes slangs that have been effectively created by and within social networks. It also describes different aspects of those slangs and sets the profile of the user of these neologisms based on the formulation of categories of analysis to interpret the data. In order to do so, it makes use of an exploratory quantitative-qualitative research, using samples of language collected in social networks. With the analysis of the collected data, it concludes that Internetese is, in fact, a neological set of the Internet and slang is a variation observed based on what its adoption and use represent.
\end{abstract}

KEYWORDS: Sociolinguistic. Slangs. Hypertexts. Internetese.

\footnotetext{
${ }^{1}$ Resultado de projeto de Iniciação Científica/Bolsa Institucional - IFSP/Campus São Paulo.

* Orientador de IC, IFSP/Campus São Paulo. Doutor em Língua Portuguesa/PUC-SP, PósDoutorado em Letras/UPM-SP e docente do IFSP/Campus São Paulo. Endereço eletrônico: flaviovaladares2@gmail.com

** Orientando de IC, IFSP/Campus São Paulo. Graduando em Letras Português-IFSP/Campus

São Paulo. Endereço eletrônico: teu.moura10@gmail.com
} 


\section{Introdução}

Com a popularização da internet, o usuário da língua passou a ocupar espaços anteriormente impensados, como o de protagonista de textos acessíveis a milhares de leitores, na maior parte das vezes, desconhecidos. Batista Junior e Silva (2010, p. 4) comentam que as redes sociais "têm como característica principal a interatividade em tempo real", o que "permite aos usuários da internet vivenciar também as mais diversas interações comunicativas".

Este artigo baseia-se na Teoria da Variação e Mudança Linguística, a partir dos estudos de Labov (1994), para a seguinte análise: as gírias construídas no espaço das redes sociais. Além disso, utilizamos o aporte referente aos estudos sobre gírias e sobre hipertexto. $O$ foco da pesquisa realizada neste artigo são as gírias usadas nas redes sociais e criadas nelas a partir de uma base lexical de Língua Portuguesa com o objetivo de analisar neologismos gírios.

Adotamos a noção de Alves (2002) para neologismo: uma unidade lexical de criação recente; uma acepção nova que se atribui a uma palavra existente; ou um termo recentemente emprestado a outro código linguístico estrangeiro. A autora afirma que todas as línguas utilizam neologismos, uma vez que a criação neológica faz parte da história delas e constitui uma evidência inequívoca de vitalidade, essencial para suprir as necessidades dos falantes e as condições de comunicação do idioma. Por neologismo gírio conceituamos a palavra/expressão que é criada na esteira lexical como um código que se restringe a um determinado grupo.

Do ponto de vista procedimental, a pesquisa realizada para este artigo é tanto quantitativa, devido ao aspecto quantificável empreendido, como qualitativa, na medida em que utiliza categorias de análise para a coleta de dados, com a interpretação dos fenômenos e a atribuição de significados aos dados analisados. Os objetivos de pesquisa, por sua vez, visam à descrição das 
características do fenômeno gírio, estabelecendo relações com os usos e os conceitos sociolinguísticos pertinentes a esses usos (GIL, 2002).

Por fim, adotamos também, como metodologia, tanto a pesquisa bibliográfica como a documental, a qual, por meio da abordagem quantitativoqualitativa demostra termos/expressões retirados das redes sociais, revelando que tal ambiente é propício para o levantamento de gírias efetivamente criadas pelas e nas redes sociais, a fim de comprovar se possuem variações e/ou derivações, seu significado no contexto de uso - redes sociais - e seu histórico. Com isso, compusemos nosso corpus de investigação: as redes sociais, mais especificamente, os sítios de relacionamento.

Assim, pretendemos, ao fim, ter descrito a relação da variação da língua no ciberespaço e traçado o perfil de usuário que se utiliza das gírias no campo virtual em suas conversas e comentários na web, bem como mostrar como se dá o processo neológico nas redes sociais, ancorados pela Teoria da Variação e Mudança Linguística, bem como pelos conceitos sobre gírias e sobre hipertextos.

\section{Gírias e hipertexto: uma apresentação conceitual}

Para Preti (1984), o aparecimento da gíria deu-se como um fenômeno restrito, decorrente da dinâmica social e linguística inerente às línguas. EO autor destaca que a gíria é caracterizada como um vocabulário especial, um signo de grupo, a princípio secreto, de domínio exclusivo de determinada comunidade social.

Preti ressalta que, quanto maior o sentimento de união entre os membros do pequeno grupo, tanto mais a linguagem gíria servirá como elemento identificador, que diferencia o falante na sociedade e serve como meio ideal de comunicação, além de também ser uma forma de autoafirmação. Afirma que

[...] quando se trata da história da gíria, conhecê-la significa penetrar no mundo da marginalidade, na vida dos grupos excluídos da sociedade pela sua própria condição de pobreza ou pelas suas atividades peculiares (não raro ilícitas), os quais buscam com a 
criação de um vocabulário criptológico uma forma de defesa de suas comunidades restritas (PRETI, 2006, p. 242)

No dicionário Houaiss e Villar (2001, p. 1453), "gíria", em sua primeira acepção, significa "uma linguagem informal caracterizada por um vocabulário rico em idiomatismos ${ }^{2}$ metafóricos, jocosos, elípticos, ágeis e mais efêmeros que os da língua tradicional". O dicionário Novo Dicionário Aurélio (FERREIRA, 1999, p. 989) a traz, em sua primeira acepção, como "linguagem de malfeitores, malandros etc, com a qual procuram não ser entendidos pelas outras pessoas". Destacamos que o Dicionário Houaiss só apresenta o conceito de gíria como linguagem de malfeitores em sua terceira acepção; diferentemente do Novo Dicionário Aurélio, que a coloca como primeira acepção e só apresenta a ideia de gíria como dialeto social, sem uma conotação pejorativa, em sua terceira acepção.

Paralelo às acepções dos dicionários comuns, há a apresentada pelos dicionários de linguística. Dubois (1973, p. 308), por exemplo, conceitua gíria como "um dialeto social reduzido ao léxico, de caráter parasita ${ }^{3}$, empregado numa determinada camada da sociedade que se põe em oposição às outras". Ainda traz que ela tem por finalidade só ser compreendida por iniciados ou mostrar que eles pertencem a um determinado grupo.

Trask (2004, p. 124), em seu Dicionário de Linguagem e Linguística, assinala que gíria é "uma forma linguística informal e frequentemente efêmera". Além disso, é exposto pelo autor que as expressões de gíria "costumam ser introduzidas por membros de um grupo social particular" e podem, ainda segundo o dicionarista e linguista, "continuar sendo típicas desse grupo e servir como uma de suas marcas de identidade ou, ao contrário, tornar-se mais amplamente conhecidas e usadas". Outro aspecto importante abordado por Trask (2004, p. 125) é que a gíria "tem sido descrita como língua em estado de

2 Idiomatismo, conforme o dicionário Houaiss, é o traço ou construção peculiar a uma determinada língua, que não se encontra na maioria dos outros idiomas. (HOUAISS; VILLAR 2001).

3 Parasita é colocado no sentido de que a gíria não faz outra coisa a não ser desdobrar, com valores afetivos diferentes, um vocabulário já existente. 
jogo, isto é, as melhores gírias são pitorescas, exuberantes, espirituosas e fáceis de lembrar".

Dessa maneira, é importante, em nossa visão, a compreensão de que a gíria nas redes sociais assume um papel de efemeridade relacionado a um jogo constante em que gírias são criadas, usadas e descartadas. Além disso, seu caráter de linguagem cifrada parece também se perder em meio aos usos que são feitos nas redes sociais, uma vez que as redes, comumente, são abertas, o que leva o vocábulo gírio a transitar muito mais como língua em estado de jogo do que propriamente um código secreto.

Isso nos encaminha, preliminarmente, a desenvolver a ideia de que o próprio conceito de gíria vem passando por alterações com o advento das redes sociais, como observamos nas acepções expostas nos parágrafos anteriores, visto que já ultrapassa sua acepção histórica e, consequentemente, firma-se como um conceito investido de criatividade e que se altera de forma muito rápida, devido à própria possibilidade efêmera de circulação que propicia criações, recriações e eliminações constantes.

Outro ponto fundamental em nossa pesquisa é o hipertexto. Marcuschi (2005, p. 13) postula que a internet, na sociedade atual, é "uma espécie de protótipo de novas formas de comportamento comunicativo" e os gêneros textuais "eletrônicos" que surgem causam impacto e polêmica tanto na linguagem como na vida social. Sua definição para gêneros virtuais dá conta de que eles são

[...] interativos, geralmente síncronos (com simultaneidade temporal), embora escritos. Isso lhes dá um caráter inovador no contexto das relações entre fala-escrita. Além da possibilidade cada vez mais comum de inserção de elementos visuais no texto (imagens, fotos etc.) e sons (músicas, vozes) pode-se chegar a uma interação com a presença da imagem, voz, música e linguagem escrita numa integração de recursos semiológicos. Quanto a isso, há outro aspecto nas formas de semiotização desses gêneros relativo ao uso de marcas de polidez ou indicação de posturas. São os conhecidos emoticons (ícones indicadores de emoção) ao lado de uma espécie de etiqueta netiana (etiqueta da internet) trazendo descontração e informalidade à formulação (monitoração fraca da linguagem), tendo em vista a volatilidade do meio e a rapidez da interação (MARCUSCHI, 2005, p. 12). 
Todos esses novos gêneros virtuais se configuram pela hipertextualidade existente neles e entre eles. A priori, segundo Xavier (2002, p. 28-29), concebe-se tal conceito - o hipertexto - como "espaço virtual inédito e exclusivo no qual tem lugar um modo digital de enunciar e construir sentido". À vista disso, compreendemos que, graças a esse novo modo de comunicação caracterizado pela manipulação, pela dinamicidade e por ser constituído de fragmentos, isto é, de diversas partes distintas, mas interconectados, há uma nova maneira de exteriorização do pensar de um único indivíduo ou de até mesmo de um grupo social (LÉVY, 1993; KOMESU, 2005; RIBEIRO, 2006).

O hipertexto é manipulável por possibilitar um rápido e fácil domínio de sua matéria e conteúdo. É dinâmico por ser composto de (hiper)links, os quais, sendo caracterizados pela arbitrariedade e pela não-linearidade, permitem maiores relações entre pessoas e instituições (XAVIER, 2002). E, por fim, é fragmentado porque, devido aos links, o autor do texto não possui a capacidade de controlar o tópico (assunto) que o leitor vai ler na internet, já que o quesito "organização" de tais fragmentos é de responsabilidade do leitor que tem acesso.

Com tal participação "ativa" do leitor, isto é, interconectando os textos (links) segundo seus interesses, mostra-se a participação do "outro" na composição do escrito. Desse modo, vemos que a constituição dos hipertextos não é apenas consoante à cognição do autor, mas sim, uma espécie de "coautoria" entre o autor e o leitor, já que este, como postulado, é responsável por "organizar" os fragmentos textuais. Corroboram com tais ideias Landow (1997) e Koch (2007) ao afirmarem que "o leitor do hipertexto é o que responde de maneira 'ativa', uma vez que as interconexões ficam sob sua responsabilidade" (LANDOW, 1997, p. 4) e também que:

No hipertexto - como, aliás em todos os demais usos da linguagem há sempre a consideração do outro, mas nele ela é levada às últimas consequências. Ainda que a única tarefa do autor fosse a marcação dos links, ele teria sempre em seu horizonte a projeção da imagem do leitor. E este será sempre co-autor, já que o acabamento do 
(hiper)texto não pode prescindir de sua participação. Trata-se, no caso, de uma alteridade multilinearizada, fragmentada, descorporalizada, volatilizada, mas fundada em nossos saberes, nossas relações com o mundo e nossa inserção em dada cultura. (KOCH, 2007, p. 35)

Portanto, a esses gêneros digitais e às suas características hipertextuais, isto é, de serem fragmentados, mas interconectarem-se e intercomunicarem-se, os aspectos linguísticos também são muito afetados. Esses aspectos, por conseguinte, comportam-se e associam-se a variadas formas e elementos, tais como imagens, sons, palavras, pessoas, mensagens multimídias etc. e, com isso, produzem diversas variações linguísticas, que são nomeadas de "internetês".

Para nosso artigo, pesquisamos os neologismos gírios nas redes sociais, como gírias criadas e inicialmente usadas nelas, com o intuito de estabelecer o modo como o ciberespaço contribui para a formação de novos termos a partir das novas configurações de interação observadas com o advento das redes sociais. A partir disso, buscamos estabelecer os sítios de relacionamento propícios à criação de gírias, bem como descrever a relação da variação da língua com o ciberespaço e traçar o perfil de usuário que utiliza tais gírias no campo virtual em suas conversas e comentários na web.

Nos procedimentos metodológicos, conforme descrito na seção anterior, selecionamos, para análise, gírias efetivamente criadas pelas e nas redes sociais, buscando apontá-las e descrevê-las de modo mais amplo possível, destacando os seguintes aspectos: a existência de variantes - diferentes nomeações para o mesmo vocábulo - ou de derivações, novos termos a partir de determinado vocábulo, mas que ainda mantém a conotação inicial; significado do termo; contexto de utilização da gíria - quando e como é usada ; e, por fim, breve comentário acerca de seu histórico.

É importante apresentar, ainda nesta seção, uma contextualização sobre o uso das redes sociais. Nesse sentido, ressaltamos que a velocidade com que nos comunicamos hoje tem influenciado a linguagem que empregamos em ambientes virtuais de conversação, tais como chats, blogs, fóruns e, 
predominantemente, redes sociais. Um exemplo que ilustra isso é a prática de abreviação de palavras, por economia de espaço e tempo, permitindo a transmissão de maior quantidade de enunciações e informações entre os usuários.

Outro exemplo, é o próprio corpus desta pesquisa: as gírias do internetês, que são analisadas segundo seu grupo de adoção e contexto de uso. Ademais, buscamos apenas aquelas que ultrapassaram os limites da internet, em um movimento centrífugo (de dentro para fora - sendo este "fora" o mundo real).

Desse modo, de uma forma geral, ainda conforme indicam Komesu e Tenani (2009), definimos rede social digital como:

[...] aquela em que um indivíduo, vinculado a um sistema constituído pela interligação de dois ou mais computadores e seus periféricos, liga-se a outro indivíduo, de outra rede, com objetivo de comunicação, de compartilhamento, de intercâmbio de dados afins, resultando na criação de novos grupos na e pela internet (RECUERO, 2006 apud KOMESU; TENANI, 2009, p. 623).

Tendo em vista isso, buscamos a rede de maior uso e repercussão de neologismos gírios e encontramos a rede social Facebook como a de maior destaque até o momento, a qual possui mais de 1.460.200.000 usuários ativos ${ }^{4}$. Além disso, é válido ressaltarmos que ela é a segunda página da web mais acessada no Brasil (perdendo apenas para o motor de busca google.com.br) e a primeira em comparação às demais redes sociais. As figuras 1 e 2 mostram a predominância do uso do Facebook atualmente, tanto no Brasil, quanto em escala internacional.

\footnotetext{
${ }^{4}$ Informação disponível no site <http://www.internetlivestats.com/watch/facebook-users>.
} 
Figura 1 - Mapa Mundial de Redes Sociais (Julho de 2014)

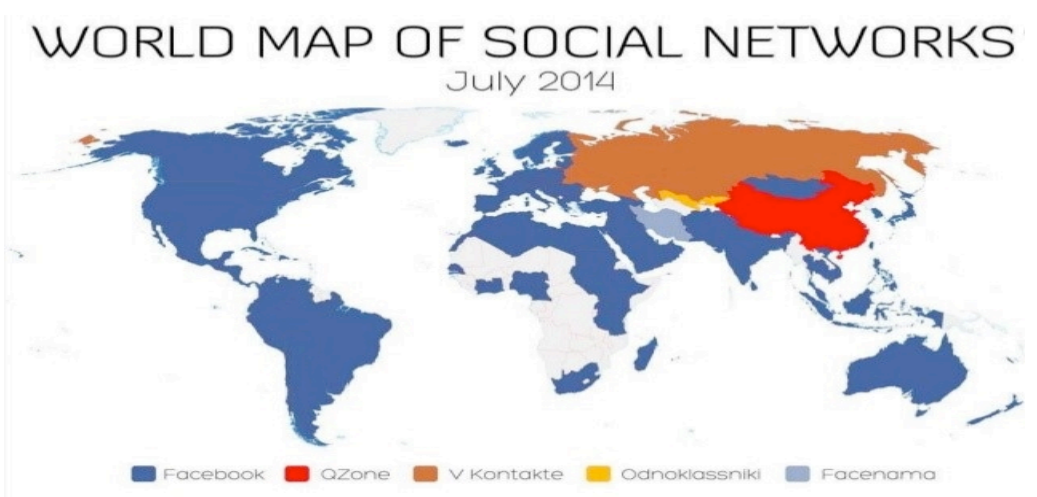

Fonte: Oliveira (2014).

Figura 2 - Ranking de acesso de redes sociais no Brasil

\section{As redes sociais no Brasil}

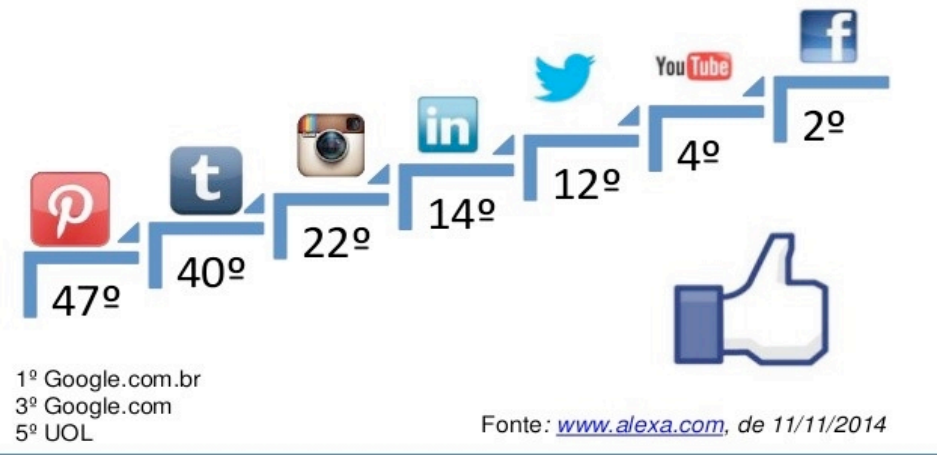

Fonte: Alexa (2015).

Quanto à frequência de utilização de gírias de internetês em chats e demais conversações virtuais, há maior frequência no grupo de pessoas que fazem parte das gerações $Y$ e $Z$. Segundo o Instituto Brasileiro de Opinião Pública e Estatística (IBOPE), esse grupo tem entre 12 e 19 anos (Geração Z), e entre 20 e 29 anos (Geração Y), totalizando em torno de 27 milhões da população total brasileira ( $41 \%$ do todo populacional). No gráfico abaixo (Figura 3), retirado da pesquisa Geração Y e Z: Juventude Digital, do IBOPE mídia, ilustramos, a partir dos Baby Boomers, as gerações efetivas da população brasileira. 
Figura 3 - Quais são as gerações do Brasil?

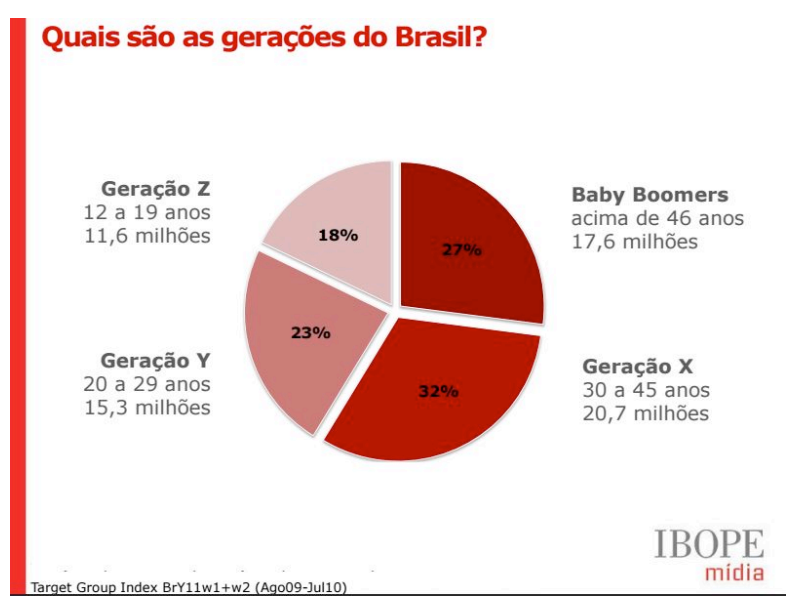

Fonte: IBOPE (2010).

As gerações $X$ e $Y$ são caracterizadas pela utilização indispensável e cotidiana de celulares, smartphones e computadores, todos com acesso à internet. São gerações cujo uso não é feito de modo passivo, pois sempre estão exteriorizando suas opiniões por meio de diversas redes sociais, e, devido a isso, a diversificação da linguagem é bastante relevante, bem como o surgimento de vários vocábulos próprios do internetês. A seguir, no segundo gráfico (Figura 4), há uma ilustração quanto ao consumo demasiado em produtos tecnológicos, o qual é característico da Geração Y e, essencialmente, da Z.

Figura 4 - Consumo Líquido das gerações brasileiras

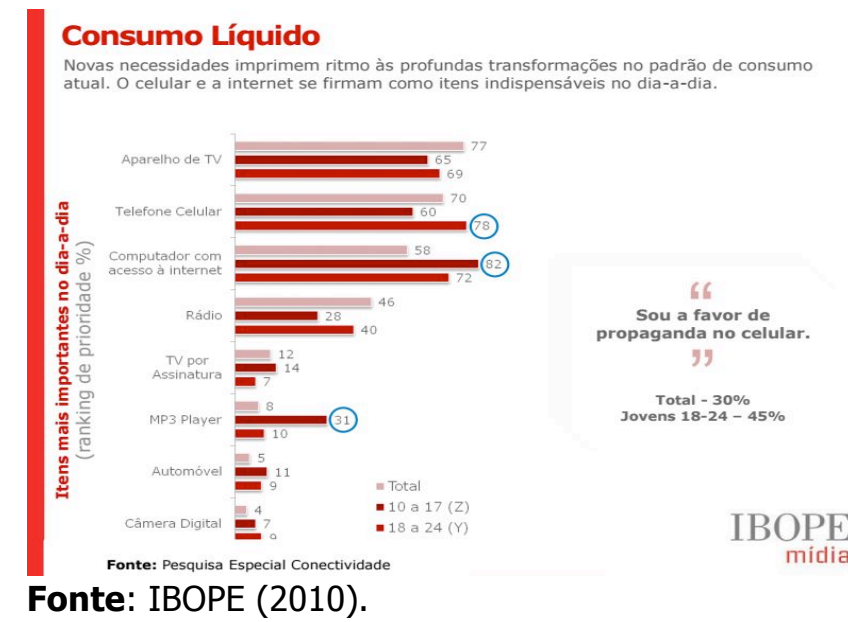


Portanto, nas palavras de Scaramal e Kraemer (2011, p. 2), os ambientes de comunicação virtual, como as salas de bate-papo, "são caracterizados pelo uso de uma nova variedade da língua portuguesa, repleta de abreviações, gírias e emoticons (símbolos que representam sentimento), sem respeito às normas ortográficas", pois "os jovens [...] agem como se estivessem conversando e não escrevendo, a linguagem tem de ser rápida, escrita de forma concisa e abreviada."

\section{Análise dos dados}

Com base nos procedimentos metodológicos descritos, nos conceitos expostos sobre gíria e sobre hipertexto, além da contextualização sobre redes sociais, apresentamos nossa análise, sob a perspectiva da Teoria da Variação e Mudança Linguística: gírias oriundas das redes sociais a partir de termos da Língua Portuguesa do Brasil - neologismos gírios.

Inicialmente, destacamos que o período de coleta compreendeu os meses de abril, maio e junho de 2015, com entradas nas redes sociais Facebook e Twitter, a partir da conta de um dos pesquisadores. Com os resultados preliminares, chegamos ao Facebook como a rede social com maior abrangência e, por causa disso, com maiores possibilidades de criação e de circulação das gírias.

De posse das informações coletadas, o critério de escolha das gírias a se analisar teve como fundamento a sua própria circulação na rede social selecionada e a considerável frequência com a qual os vocábulos gírios eram utilizados no espaço virtual. Além disso, o fato de eles circularem, em princípio, apenas no Facebook e a possibilidade de categorização como neologismos gírios indicaram o caminho qualitativo para a análise da coleta.

Do ponto de vista da variação, Preti (2006, p. 248) defende que a gíria se incorporou a algumas variedades de registros e dialetos sociais. Nessa perspectiva, ao considerarmos os pressupostos de Weinreich, Labov e Herzog (2006), também consideramos que as variações, no caso específico das gírias, inserem-se como condicionantes possíveis, uma vez que são criadas, 
observando-se a estrutura da língua e são caracteristicamente utilizadas por um grupo específico, mantendo seu conceito inicial de linguagem cifrada.

Aprioristicamente, a gíria passa por um estágio de transição, no qual poderá, por encaixamento, haver o entrelace das estruturas linguística e social e, ao se disseminar, - observamos isso a partir do Facebook -, coloca-se como tendo sido aceita pela comunidade linguística. A partir disso, temos a avaliação cujos efeitos irão figurar sobre a estrutura e o uso, daí ocorrerem derivações, por exemplo. Em se passando por tais estágios, podemos confirmar que terá havido a implementação. Evidentemente, nos casos dos neologismos gírios, todo o processo de variação é muito mais rápido para se atestar se seu uso foi ou não adotado e até mesmo se permanecerá por muito mais tempo ou não, como mostramos nos exemplos selecionados das redes sociais, em análise neste artigo a seguir:

A primeira gíria selecionada é "acertou mizeravi!", que apresenta derivações e/ou variações, como "Acertô Mizeravi", "Mizerave(i)", "Ah, Mizerarvi", "Acertô Mizeravi, ken tim sinô?". Em nossa análise, de acordo com o contexto de produção, tal expressão tem por objetivo ironizar o erro de outrem, sendo utilizada de dois modos distintos: o primeiro está relacionado às situações em que usuário ou o sujeito possui uma suposta conviç̧ão de que acertou operações matemáticas básicas absurdamente equivocadas. Já o segundo uso é mais generalizado, isto é, abrange diversos erros absurdos, sejam equívocos gramaticais, ou então raciocínios, frases variadas etc.

A pesquisa chegou ao seguinte histórico da gíria: ela surgiu a partir de um vídeo no Youtube, intitulado "Acertou Mizeravi!", postado em 26 de novembro de $2014^{5}$. Tal vídeo apresenta um adolescente que está respondendo perguntas relacionadas a operações matemáticas simples (soma, multiplicação etc.). No entanto, constatamos que todas as respostas do garoto ao questionador são equivocadas, tornando o feito cômico; a partir disso, ela repercutiu em diversas redes sociais.

\footnotetext{
${ }^{5}$ Disponível em: <https://www.youtube.com/watch?v=8dHQK6SdEok>.
} 
A gíria Acertou Mizeravi ou, simplesmente, Ah! Miseravi, tornou-se popular a partir de um vídeo vinculado no Youtube. Observamos como tais redes sociais estão vinculadas quanto ao compartilhamento de informações e, no caso, de expressões virais do internetês. Outro ponto é a efemeridade e também o uso diversificado dessa gíria, desde seu surgimento, tendo em vista que ela passou a ser empregada em outros contextos e em outras páginas da internet e que, portanto, passou a não possuir um grupo de usuários específicos.

A segunda gíria selecionada é "Amanda nudes", para a qual verificamos existir derivações, tais como o sobrenome de cada "Amanda", normalmente composto por um substantivo concreto - "Cruz", "Correia", por exemplo. Seu significado é o de uma solicitação sarcástica de fotos nuas de um determinado usuário, sendo as mulheres com o primeiro nome "Amanda" o público primordial a que se destina. Isso ocorre porque o nome "Amanda" tem sonoridade parecida com: "Ah, manda...", tornando-se um pedido de algo, pois o "A-" inicial torna-se, nesse caso, uma interjeição, e "manda", um verbo no imperativo.

O contexto de uso que tal gíria possui é diversificado, tendo em vista que ela se apresenta de modo súbito e com o intuito de apenas zombar ou irritar as usuárias com nome "Amanda" que possuem sobrenomes compostos por substantivos concretos. Em seu histórico, buscando-se o termo em algumas redes sociais - Facebook e Twitter - e em blogs, observamos que ele e suas variações são bem recentes.

Uma de suas prováveis origens decorre de uma foto usada, a priori, no aplicativo de mensagens instantâneas WhatsApp, em que haveria um trocadilho com o nome e o sobrenome de uma mulher e, sequencialmente, um meme ${ }^{6}$ ironizando o termo. A expressão, inicialmente, seria "Manda nudes", mas, devido à sonoridade semelhante com que se pronuncia Amanda juntamente à

\footnotetext{
6 "Meme" é um fenômeno de viralização de uma determinada informação na internet, podendo ser um vídeo, uma imagem, uma música etc. Caracteriza-se por sua rápida expansão em mídias digitais, tais como blogs, sites de notícias, redes sociais e demais fontes de informações virtuais.
} 
palavra "nudes", houve a formulação de um neologismo gírio do internetês, mas com o mesmo teor sarcástico e imperativo.

Após isso, em decorrência do viral compartilhamento de tais trocadilhos, a gíria logo passou a ser utilizada nas demais redes sociais: seus primeiros usos com esse sentido aconteceram no início do mês de maio de 2015, tanto no Twitter, quanto no Facebook, e também em demais sites e blogs.

Nessa expressão do internetês, uma característica muito interessante a ser salientada é a questão fonética, pois a gíria "Amanda Nudes" é derivada da proximidade (ou até mesmo semelhança) fonética existente entre o " $\mathrm{A}$ " inicial do nome próprio Amanda e da interjeição "Ah!", a qual permite a construção de sentido própria do termo, isto é, o de mandar algo, no caso, "nudes", fotos nuas ou seminuas. Com isso, podemos inferir a dinamicidade não apenas do neologismo gírio, mas também, de como o léxico pode se enriquecer a partir da criatividade linguística.

Observamos também o uso dessa expressão para além da conotação mencionada acima, ou seja, utilizou-se ainda o sentido imperativo decorrente da proximidade sonora já descrita para agora fazer brincadeiras virtuais sobre as mulheres com o nome de Amanda. Desse modo, aquelas que possuíam esse nome mais um sobrenome de substantivo concreto eram, em geral, vítimas de tais galhofas em chats do Facebook. 
Figura 5 - Exemplo do uso da expressão "Amanda + substantivo concreto", no Facebook.

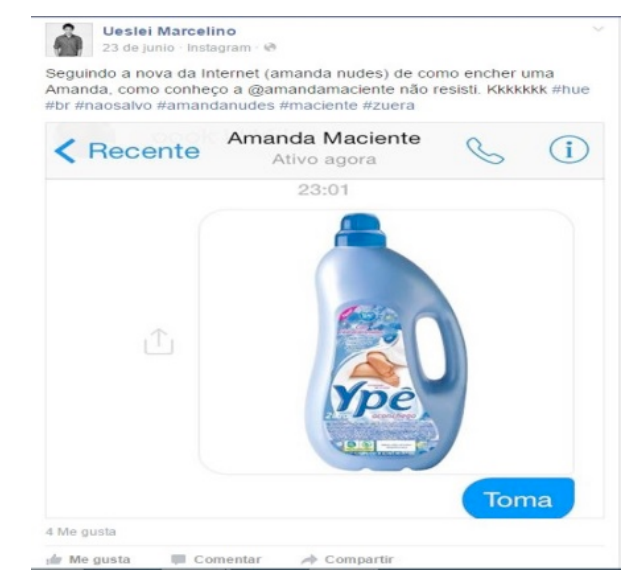

Fonte: Marcelinho (2015).

A terceira gíria em análise é "coveiragem". Há as derivações "coveiro" "aquele que pratica a coveiragem"; "coveirar" - "ato de coveiragem"; e "coveirado" - adjetivação do vocábulo. Seu significado é "desenterrar" certo tópico (para blog) e/ou comentário (no Facebook) que há anos foi, teoricamente, findado. Em outras palavras, tal gíria seria quando, por exemplo, algum usuário comenta hoje algo em determinado comentário ou tópico já "encerrado" em 2005, por exemplo.

O uso de tal gíria possui dependência do tempo, pois só ocorre coveiragem quando há certa distância temporal entre o comentário original e outro comentário posterior, que, muitas vezes, não possui nexo. Na pesquisa de seu histórico, por meio do motor de busca do Google, encontramos, inicialmente, coveiragens em fóruns de discussão. O mais antigo tópico "coveirado" constatado pela pesquisa foi o do fórum Growroom, datado em 26 de setembro de $2002^{7}$. Posteriormente, tal gíria foi empregada e esse tópico pôde ser "desenterrado", isto é, comentado novamente pelo usuário Bicudoman, em 24 de junho de 2013, e mais algumas vezes em 2014. Com o

\footnotetext{
${ }^{7}$ Informações no site: <http://www.growroom.net/board/topic/2315-florescer-comfluorescentes/>.
} 
surgimento do Facebook, tal hábito de usuários de fóruns foi "transferido" para os comentários nas redes sociais.

Ao analisarmos essa gíria, notamos que ela possui uma característica muito interessante e distinta em comparação às outras gírias, ou seja, enquanto algumas são bem efêmeras (tidas como "modinha" pelos próprios usuários) ou apresentam um longo período de uso. Ela, na verdade, depende justamente do tempo para ser utilizada e, por isso, sendo subordinada a elementos antigos, como tópicos ou comentários de anos passados, por isso, só é possível seu emprego nos anos sucessores.

Nesse sentido, os administradores de blogs, em geral, criaram regras para que tal atitude, às vezes desagradável ou desnecessária, não aconteça novamente. Já na rede social Facebook, tal atitude é vista de modo diferente: simplesmente como algo cômico, pois o "coveiro" retorna na timeline ${ }^{8}$ de um usuário para simplesmente "desenterrar" algo de lá, seja comentário, foto, vídeo etc. Algo que as pessoas cadastradas não veem de modo negativo, uma vez que em nada as prejudica.

A quarta gíria é mitar, que significa sobretudo comentar algo (engraçado, criativo e/ou inteligente), e receber centenas ou, até mesmo, milhares de "curtidas", na rede social Facebook. Além disso, refere-se a alguém (atleta, músico etc.) que possui grande habilidade em sua respectiva área de atuação profissional. Ela também recebe variantes, como "Mito" - aquele que recebe diversas "curtidas", "mitância" - conjunto de "mitos" (pessoas muito boas em algo, como na comédia, na música etc.). Além disso, tal termo também é atribuído a uma pessoa que é muito boa ou possui grande habilidade em algo. Além disso, derivações, como "mitagem" - ato de mitar , "submito" aquele que comenta posteriormente acerca do mito e "mitada" - comentário de grande repercussão.

O uso desse internetês ocorre quando um usuário recebe grande quantia de "curtidas" e é tido como um "mito", tornando o comentário um dos

\footnotetext{
${ }^{8}$ Significa linha do tempo, tendo um uso nas redes sociais associado à ordem das publicações, auxiliando o internauta a se localizar, ao exibir as últimas postagens feitas por amigos, por exemplo.
} 
principais, isto é, de grande repercussão, como forma de elogio. Tal termo ganhou grande repercussão em meados de 2013, na fanpage 9 "Fatos Desconhecidos" e, até hoje, é assiduamente usado pelos usuários do Facebook. Inicialmente, a gíria decorreu do movimento de "caçada às curtidas" nos comentários, que fez com que "mitar" designasse comentários criativos e, em grande parte, engraçados ao público-leitor. Posteriormente, também foi agregada a conotação de elogio, de trazer certo prestígio a um determinado usuário da web.

Podemos destacar dois pontos relevantes nessa gíria e que também se tornaram frequentes nos vocábulos ulteriores - em especial os que advêm de empréstimos linguísticos - a saber, a verbalização e a substantivação do termo. Ademais, também observamos no quesito de derivações o acréscimo de prefixo ao vocábulo, como exposto em submito.

Outra questão a ser pontuada é que, apesar da grande maioria dos termos gírios do internetês ser efêmera e, portanto, possuir uma duração de uso bem escassa, essa não se encaixa em tais parâmetros, tendo em vista que já possui quase dois anos de atividade, sem nenhum indício de desuso. Posto isso, vemos que é apenas uma exceção, visto que, como se mostrará, em grande parte, tais vocábulos são virais em períodos de tempo diversos, mas são também rápidos em suas utilizações e tornam-se obsoletos.

\section{Conclusão}

Ao término desta pesquisa, tomando por base a afirmação de Trask (2004, p. 124), concluímos que as gírias são "uma forma linguística informal e frequentemente efêmera" pois, essencialmente no campo cibernético, de fato, são informais, devido ao contexto e modos de uso descontraídos, sem a necessidade de quaisquer policiamentos linguísticos. Elas são principalmente efêmeras, visto que são construídas a partir de elementos virtuais, como vídeos e imagens que, devido à rápida troca de informações proporcionada pelos

\footnotetext{
${ }^{9}$ Significa página de fãs. Funciona como uma página específica dentro do Facebook. Tem um caráter mais profissional que pessoal.
} 
atuais mecanismos de comunicação, têm seu momentâneo ápice de uso e de compartilhamento, mas que, no decorrer de algum tempo, tornam-se quase inutilizáveis, dando lugar a outros neologismos gírios, que são reinventados e desenvolvidos a cada momento no ciberespaço, no caso da coleta realizada nesta pesquisa, por meio de vocábulos próprios da língua portuguesa.

Entretanto, com o desenvolver da pesquisa, também é válido postularmos que, além da efemeridade existente em algumas gírias, também há certa variedade no tempo de duração de uso, pois constatamos que algumas delas já possuem um grande período de atividade, tais como "mitar" e "coveiragem". Assim, nesse aspecto - o de atividade e desuso de gíria - ora o vocábulo é momentaneamente usado, ora se prolonga até os dias de hoje.

Além disso, é válido ressaltarmos como tais neologismos gírios são exteriorizações de sentimentos e/ou de pensamentos no âmbito virtual e que, quando realizados nas redes sociais, são utilizados no mundo real. Ou seja, há a constatação de um movimento centrífugo da utilização de tais termos - quer dizer, um movimento de dentro (mídias digitais: redes sociais, internet etc.) para fora (mundo real).

Dessa maneira, a contribuição para nosso léxico ocorre por meio de fenônemos de derivações e de variações das gírias, a saber, substantivações, verbalizações e adjetivações, os quais tornam a língua mais rica e apresentam as não aceitas, mas possíveis formas compostas pelos falantes nativos do português, tendo em vista que tal língua propicia variadas formas de construção de vocábulos.

Encerramos este artigo com a convicção de que o internetês é, com efeito, um conjunto neológico da internet e que a gíria é uma variação observada pelo que representa sua adoção e uso em cada contexto e local virtual analisado, ainda que substancialmente seja, em sua grande maioria, uma utilização por usuários das duas últimas gerações, a saber, a Geração $Y$ (aqueles que nasceram entre 1980 e 2000) e a Geração Z (a qual abarca aqueles que nasceram após o ano 2000). 


\section{Referências}

ALEXA. Disponível em: <http://www.alexa.com>. Acesso em: 15 out. 2015.

ALVES, Ieda Maria. Neologismo: criação lexical. São Paulo: Ática, 2002.

BATISTA JUNIOR, José Ribamar Lopes; SILVA, Francisco das Chagas Rodrigues da. Gêneros textuais, virtuais e rede sociais: práticas de leitura e escrita no ensino médio profissionalizante. In: SIMPÓSIO HIPERTEXTO E TECNOLOGIAS NA EDUCAÇÃO REDES SOCIAIS E APRENDIZAGEM, 3., 2010, Recife. Anais... Recife: UFPE: Núcleo de Estudos de Hipertexto e Tecnologia na Educação, 2010.

DUBOIS, Jean (Org.). Dicionário de linguística. São Paulo: Cultrix, 1973.

FERREIRA, Aurélio Buarque de Holanda. Novo Aurélio Século XXI: o dicionário da língua portuguesa. Rio de Janeiro: Nova Fronteira, 1999.

GIL, Antonio Carlos. Como elaborar projetos de pesquisa. 4. ed. São Paulo: Atlas, 2002.

HOUAISS, Antonio; VILLAR, Mauro de Salles. Dicionário Houaiss da língua portuguesa. Rio de Janeiro: Objetiva, 2001.

IBOPE - Instituto Brasileiro de Opinião Pública e Estatística. Gerações Y e Z: juventude digital. 2010. Disponível em: <http://www.ibope.com.br/ptbr/noticias/Documents/geracoes\%20_y_e_z_divulgacao.pdf>. Acesso em: 24 ago. 2015.

KOCH, Ingedore G. Villaça. Hipertexto e construção do sentido. Alfa, São Paulo, 51 (1): 23-38, 2007.

KOMESU, Fabiana; TENANI, Luciani. Considerações sobre o conceito de "internetês" nos estudos da linguagem. Linguagem em (Dis)curso, Palhoça, v. 9, n. 3, p. 621-643, set./dez. 2009.

LABOV, William. Padrões sociolinguísticos. Tradução de Marcos Bagno, Maria Marta Pereira Scherre e Caroline Rodrigues Cardoso. São Paulo: Parábola Editorial, 2008.

LABOV, William. Principles of linguistic change. Oxford: Blackwell, 1994. v. 1

LANDOW, George P. Hypertext 2.0: the convergence of contemporary critical theory and technology. Baltimore, Maryland: Johns Hopkins, 1997.

LÉVY, Pierre. As tecnologias da inteligência: o futuro do pensamento na era da informática. São Paulo: 34, 1993. 
MARCELINO, Ueslei. Amanda maciente. 2015. Disponível em:

<https://www.facebook.com/photo.php?fbid =858329667537565\&set=p.85832

9667537565\&ty pe=3\&theater>. Acesso em: 15 out. 2015.

MARCUSCHI, Luiz Antonio. Gêneros textuais emergentes no contexto da tecnologia digital. In: MARCUSCHI, Luiz Antonio; XAVIER, Antonio Carlos. (Org.). Hipertexto e gêneros digitais. Rio de Janeiro: Lucerna, 2005. p. 13-67.

OLIVEIRA, Mauro de. As mudanças na comunicação e o uso adequado de redes sociais. 2014. Disponível em: <http://pt.slideshare.net/maurojornalista/asmudanas-na-comunicao-e-o-uso-adequado-de-redes-sociais-anhembi-morumbie>. Acesso em: 15 out. 2015

PRETI, Dino. A gíria e outros temas. São Paulo: Edusp, 1984.

PRETI, Dino. A gíria na língua falada e na escrita: uma longa história de preconceito social. In: PRETI, Dino. (Org.). Fala e escrita em questão. São Paulo: Associação Editorial Humanitas, 2006. v. 4, p. 241-255.

RIBEIRO, Ana Elisa. Leituras sobre hipertexto: trilhas para o pesquisador?. In: SIMPÓSIO NACIONAL DE LETRAS E LINGUÍSTICA, 11., SIMPÓSIO INTERNACIONAL DE LETRAS E LINGUÍSTICA, 1., 2006, Uberlândia. Anais... Uberlândia, 2006. Disponível em: <https://www.ufpe.br/nehte/artigos/ Leituras\%20sobre\%20hipertexto.pdf>. Acesso em: 15 out. 2015.

SCARAMAL, Junior; KRAEMER, Alessandro. A influência da internet nas variações linguísticas. In: CONGRESO ARGENTINO DE CIENCIAS DE LA COMPUTACIÓN, 17., La Plata. 2011. Anais... La Plata:UNLP, 2011. p. 461-468.

TRASK, Robert Lawrence. Dicionário de linguagem e linguística. São Paulo: Contexto, 2004.

WEINREICH, Uriel; LABOV, William; HERZOG, Marvin. Fundamentos empíricos para uma teoria da mudança linguística. Tradução de Marcos Bagno. São Paulo: Parábola Editorial, 2006.

XAVIER, Antonio Carlos dos Santos. Hipertexto na sociedade da informação: a constituição do modo de enunciação digital. 2002. Tese (Doutorado em Linguística) - Universidade Estadual de Campinas, Campinas, 2002. 